www.jmscr.igmpublication.org

Index Copernicus Value: 79.54

ISSN (e)-2347-176x ISSN (p) 2455-0450

crossrefDOI: https://dx.doi.org/10.18535/jmscr/v7i3.32

\title{
Profile of congenital surgical anomalies among admitted neonates - A retrospective study from a rural tertiary care centre, South India
}

Authors

Mohanavel Pannerselvam ${ }^{1}$, Harikrishnan Elangovan ${ }^{2 *}$, Karthick $\mathbf{E}^{2}$

${ }^{1}$ Department of Paediatric Surgery, ${ }^{2}$ Department of Paediatrics

Government Villupuram Medical College, Villupuram

*Corresponding Author

Dr Harikrishnan Elangovan, MD (Paediatrics)

Associate Professor of Paediatrics, Government Villupuram Medical College, Villupuram, India

Phone No: 9884904428, Email: harie82@gmail.com

\begin{abstract}
Introduction: Congenital anomalies (CAs) are common and are one of the leading causes neonatal and childhood mortality and morbidity. The present study thus endeavours to estimate the burden of congenital surgical anomalies in a tertiary care centre so that the information can be used to prioritize resources for prevention and control.
\end{abstract}

Methods: This is a retrospective hospital-based one year study. Information regarding maternal age, parity, risk factors like consanguinity and bad obstetric history were recorded. Neonatal information like type of congenital anomaly and system affected, gestational age, sex, birth weight, need for resuscitation, APGAR score in the neonate and outcomes were recorded. All the congenital anomalies were classified as per International Classification of Diseases version 10 (ICD - 10).

Results: Out of 3747 admissions, 2800 babies were inborn and 947 were out born. The total number of babies with congenital anomalies was 118, of which 77 babies have surgical anomalies. Male and female babies are equally affected (1:1). Higher frequency of congenital surgical anomalies were seen in term babies (74\%), normal birth weight babies (59.7\%) and born to mothers aged 21-25 years (51.9\%). The most common system involved is Cleft lip and palate (19) with combined cleft lip and palate (12) as the most common anomaly. Out of 77 babies, 60 were discharged, 8 were referred and 9 were expired in the immediate neonatal period.

Conclusion: This study shows that the congenital malformations are still a burden to address and the pattern of congenital surgical anomalies varies from centre to centre. Similar multi-centric studies would contribute the understanding of pattern and prevalence of congenital anomalies which enables the government to plan appropriate intervention measures and its timing to reduce the early childhood morbidity.

Keywords: Congenital Anomalies, Surgical Anomalies, Neonates.

\section{Introduction}

Congenital anomalies (CAs) are common and are one of the leading causes neonatal and childhood mortality and morbidity. According to WHO, congenital anomalies are defined as structural or functional anomalies, including metabolic 
disorders that occur during intrauterine life and can be identified prenatally, at birth or sometimes may be only detected later in infancy ${ }^{[1]}$. Congenital anomalies accounts for $11 \%$ of neonatal deaths globally and $9 \%$ in India ${ }^{[2]}$. The prevalence of congenital anomalies in India is $6-$ $7 \%{ }^{[3]}$. Tamil Nadu has an infant mortality rate of 17 per 1000 live births, against the national average of 34 per 1000 live births ${ }^{[4]}$. After the up gradation of newborn units by National Rural Health Mission, mortality and morbidity due to asphyxia and prematurity have reduced. However, the mortality and morbidity due to congenital anomalies continues to be an important cause of neonatal morbidity and mortality. In developing countries, maternal infections and malnutrition contribute to the occurrence of congenital anomalies. Congenital anomalies are an important challenge to bring significant reduction in neonatal mortality and long-term care of survivors demand huge resources and social support. Therefore, it is important that the burden of CAs is reflected appropriately.

Congenital anomalies can be limited by detection using proper antenatal sonograms. With the era of advanced ultrasound diagnostics, most of the major anomalies are detectable prenatally. Detection of these prenatally, has resulted in fetal intervention or surgical correction in the immediate post natal period or offer termination of pregnancy for lethal conditions. However, prevention of congenital anomalies is unfortunately becomes impossible. So it is necessary to understand the pattern of congenital anomalies so that we can plan appropriate measure to prevent and to plan a program that provides timely intervention and reduce the mortality and morbidity of the same. As there were numerous studies that enumerate the pattern of congenital anomalies in newborn, anomalies requiring surgical intervention are limited in our country. The present study thus endeavours to estimate the burden of congenital surgical anomalies in a tertiary care centre so that the information can be used to prioritize resources for prevention and control.

Although underreporting, deficiencies in diagnostic capabilities, and poor follow-up at birth may affect the report of congenital malformations, the actual prevalence of congenital anomalies in Africa probably differs from that in the developed world due to differences in exposure to e.g. maternal infections and malnutrition

\section{Materials and Methods}

This is a retrospective hospital-based study done in Department of Paediatrics, in a rural tertiary care centre in south India. The records of admitted neonates for a period of one year from January 2018 to December 2018 were analyzed. Approval from the Institutional Ethical Committee was taken prior to the commencement of the study.

Medical records of all neonates admitted in our hospital during the study period were collected and scrutinized from which neonates with congenital anomalies were included in the study. The neonates born in the hospital and admitted were categorized as "inborn" and those which were referred from elsewhere for admission were labelled as "out born" in the study. Congenital anomalies due to cardiac conditions, intrauterine deaths and stillbirths were excluded from the study. Information regarding maternal age, parity, risk factors like consanguinity and bad obstetric history were recorded. Neonatal information like type of congenital anomaly and system affected, gestational age, sex, birth weight, need for resuscitation, APGAR score in the neonate and outcomes were recorded.

Data entry was done in Microsoft Excel Version 2007 and analysed using SPSS software version 20.0. All the congenital anomalies were classified as per International Classification of Diseases version 10 (ICD - 10) as disorders of central nervous system (Q00-07), face, neck eye and ear development excluding orofacial clefts (Q10-18), circulatory system (Q20-28), respiratory system (Q30-34), cleft lip and cleft palate (Q35-37), gastrointestinal system (Q38-45), genital organs 
(Q50-56),

urinary

musculoskeletal system

system(Q60-64), malformations (Q80-89) and chromosomal abnormalities (Q90-99).

Statistical analysis: The categorical variables like gender, proportion of congenital anomalies, proportion of inborn and out born admissions, parity, and consanguinity were summarized as percentages.

\section{Results}

In the one year study period, total number of neonates admitted in our hospital was 3747, of which 2800 were inborn and 947 babies were born outside. Of total admissions, 118 babies had congenital malformations The proportion of congenital anomalies among admitted neonates was 3.15\%. Among 118 anomalous babies, 77 were due to surgical anomalies excluding cardiac anomalies, contributing to $65 \%$ of overall anomalies. (Table 1)

The ratio of congenital surgical anomalies between male and female babies is 1:1. Higher proportion of term babies (74\%) were anomalous compared to preterm babies (26\%).On analysing the birth weight of babies born with congenital surgical anomalies, 47 babies $(59.7 \%)$ were born with birth weight of more than $2.5 \mathrm{kgs}, 24$ babies (31\%)were born with Low Birth Weight (1.5 - 2.5 $\mathrm{Kg}$ ) , 4 babies (5\%) were born with Very Low Birth Weight (1-1.5 Kg) and 2 babies (2.6\%) were born with Extremely Low Birth Weight $(<1 \mathrm{Kg})$.

On analysing the maternal age, 11 babies (14.3\%) were born to mothers aged less than 20 years, 40babies $(51.9 \%)$ were born to mothers aged between 21-25 years, 19babies (24.7\%) were born to mothers aged between 26-30 years, and 7 babies $(9.1 \%)$ were born to mothers aged above 30 years. Surgical malformations were common among multiparous mothers $(50,64.9 \%)$ as compared to primi mothers $(26,33.8 \%)$. Thirteen mothers $(16.9 \%)$ had previous bad obstetric history with previous abortions. All the above said parameters are represented in Table 2.

The system wise distribution of surgical anomalies as per the ICD-10 system is given in Table 3. The most common among them were cleft lip and cleft palate in 19 babies (24.5\%). Among those with cleft lip and cleft palate, the most common type was combined clefting of lip with palate seen in 12 babies. The next most common system involved was central nervous system affecting 17 babies (22.1\%). Fourteen babies $(18.2 \%)$ had anomalies of musculoskeletal system. In central nervous system, meningomyelocele was most common type (13 babies). CTEV and imperforate anus was common in musculoskeletal and gastro-intestinal system respectively.

Of 77 neonates affected with congenital surgical anomalies, 60 babies got discharged in neonatal period, 8 cases were referred and 9 cases were died. The proportion of mortality in congenital surgical anomalies was $11.7 \%$ and the most common system involved is central nervous system with meningomyelocele as the most common anomaly.

Table -1 Admission Profile of neonates with congenital anomalies in the one year study period

\begin{tabular}{|l|c|c|c|}
\hline Parameter & Inborn & Out born & Total \\
\hline Neonates Admitted & 2800 & 947 & 3747 \\
\hline Babies with Congenital Anomalies & 74 & 44 & 118 \\
\hline Babies with Congenital Anomalies of non-cardiac cause & 46 & 31 & 77 \\
\hline
\end{tabular}

Table - 2 Characterization of neonates with congenital surgical anomalies

\begin{tabular}{|l|l|c|c|}
\hline S.No & & No. of Cases & Percentage of Cases \\
\hline 1 & Gender & 38 & 49.4 \\
\hline & Male & 39 & 50.6 \\
\hline & Female & & \\
\hline 2 & Maturity & 20 & 26.0 \\
\hline & Preterm &
\end{tabular}




\begin{tabular}{|l|l|c|c|}
\hline & Term & 57 & 74.0 \\
\hline 3 & Birth Weight & & \\
\hline & $<1 \mathrm{Kg}$ & 2 & 2.6 \\
\hline & $1-1.5 \mathrm{Kg}$ & 4 & 5.2 \\
\hline & $1.5-2.5 \mathrm{Kg}$ & 24 & 31.2 \\
\hline & $>2.5 \mathrm{Kg}$ & 47 & 61.0 \\
\hline 4 & Maternal age & 11 & \\
\hline & $<20$ Years & 40 & 14.3 \\
\hline & $21-25$ Years & 19 & 51.9 \\
\hline & $26-30$ Years & 7 & 24.7 \\
\hline & $31-35$ Years & & 9.1 \\
\hline & $>35$ Years & & \\
\hline 5 & Parity & 26 & 33.8 \\
\hline & Primi & 51 & 66.2 \\
\hline & Multiparous & & \\
\hline 6 & Bad Obstetric History & 13 & 16.9 \\
\hline & Present & 64 & 83.1 \\
\hline & Absent & & 14.3 \\
\hline 7 & Consanguinity & 11 & 85.7 \\
\hline & Present & 66 & \\
\hline & Absent & & \\
\hline
\end{tabular}

Table -3 System-wise distribution of congenital surgical anomalies in the study

\begin{tabular}{|l|c|}
\hline System involved (N,\%) & Type of Malformation $(\mathrm{N}, \%)$ \\
\hline \multirow{2}{*}{ CNS $(17,22.1)$} & Meningomyelocoele $(13,16.8)$ \\
\cline { 2 - 2 } Cleft Lip and Palate $(19,24.5)$ & Hydrocephalus $(4,5.1)$ \\
\cline { 2 - 2 } & Cleft Lip with Palate $(12,15.5)$ \\
\cline { 2 - 2 } & Cleft Lip $(3,3.9)$ \\
\hline \multirow{3}{*}{ GIT $(9,11.7)$} & Cleft Palate $(4,5.1)$ \\
\cline { 2 - 2 } & Tracheo-Esophageal Fistula $(2,2.5)$ \\
\cline { 2 - 2 } GUT $(5,6.5)$ & Diaphragmatic Hernia $(3,3.9)$ \\
\hline \multirow{3}{*}{ Musculoskeletal $(14,18.2)$} & Imperforate Anus $(4,5.1)$ \\
\hline Others $(13,16.8)$ & Congenital Dysplasia of Hip \\
\cline { 2 - 2 } & $(3,3.9)$ \\
\hline
\end{tabular}

Chart 1 Outcome of Babies with congenital surgical anomalies

\section{Outcome}

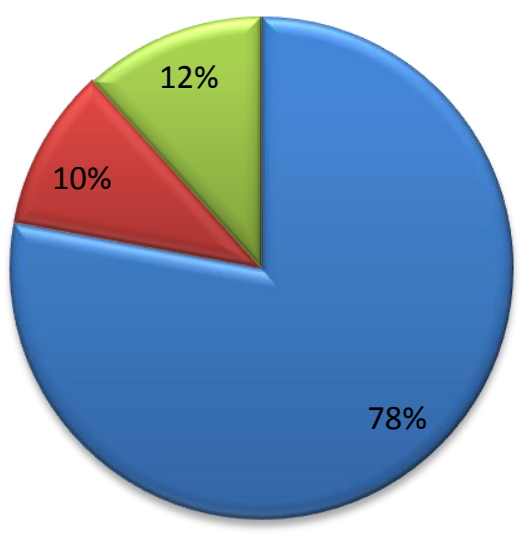

Discharged

Referred

$\triangle$ Expired 


\section{Discussion}

In our present study, the proportion of congenital anomalies was $3.15 \%$, which is comparable to earlier studies from India and other parts of world, reported to be $3 \%$ as in Tanzania and Hyderabad [5], [6]. The status among developed countries is not much different ranging from $2-3 \%{ }^{[7]}$. This reinforces the fact that despite robust antenatal services and periodic ultrasound screening, it may not be feasible to bring the occurrence to congenital anomalies to nil.

Congenital anomalies were seen in a higher proportion (74\%) of newborns born at term and in those with birth weight more than $2.5 \mathrm{~kg}$ (59.7\%) in our study. The proportion of anomalous newborns with low birth weight was $31 \%$. Studies have had a similar observation as ours (Pandala et

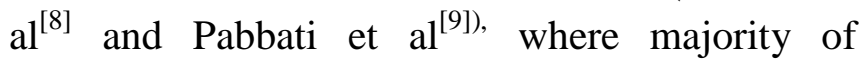
anomalous babies were born between 37 weeks to 40 weeks. This is usually contrary to that reported in literature that greater incidence of congenital malformations occur among newborns with prematurity and LBW.

According to literature, the biological fragility of the male fetus, make them susceptible to higher risk from obstetric catastrophes culminating in a higher incidence of congenital deformities in males. However, such an observation was not seen in our study. We had an equal distribution of congenital anomalies across both the gender (1:1) [10].

Earlier studies have shown a U shaped pattern with regard to maternal age for the occurrence of congenital anomalies with higher incidence of CA reported in mothers aged below 20 years and above 30 years. While in our study this pattern was evident. We observed higher proportion of CAs among mothers aged between 21-25 years. This could be due to a decrease in teen age pregnancies in the community for fear of litigation and awareness of ill effects of the same. In the rural community that we cater to, a tendency to complete the family occurs by 30 years of age thereby decreasing the frequency of elderly pregnancies as well. This could attribute to a higher proportion of pregnancies within 21-30 years of age and therefore incidentally a higher frequency of CA in this age group ${ }^{[10]}$. In our study, $16 \%$ of women having anomalous babies had history of previous abortions. It is well known from the literature that chances of CAs are $4-6$ times higher among pregnancies terminating in stillbirths and miscarriages ${ }^{[10]}$.

With regard to the pattern of surgical CA in our study, the most common surgical anomaly was combined cleft lip and palate. The spectrum of CAs worldwide differs. Studies done in various parts of India by Karla et al, Suguna Bai et al and Mathur et al shows highest incidence of anomalies were Central Nervous System, GIT and Musculoskeletal respectively ${ }^{[11],[12],[13]}$. The relative differences in the occurrence of Congenital Anomalies were due to geographic and racial differences.

Prevalence of orofacial clefts is 11- 15.3 per 10,000 live births ${ }^{[14]}$. Prenatal diagnosis of these anomalies helps in psychological preparation of parents because of cosmetic implications of the neonate and adequate postnatal management. Despite advances in sonographic technology, the sensitivity for detection of facial clefts remains poor. Involvement of the foetal palate is an important finding that will determine the requirement for surgery, audiology and orthodontic services well into teenage years ${ }^{[15]}$. Functional and cosmetic repair are usually completed before the age of 10 .

Meningomyelocele is the most common congenital anomaly of the central nervous system compatible with long tern survival and is associated with significant lifelong disabilities in affected children. The incidence can be decreased up to $70 \%$ when daily folic acid supplements are taken prior to conception ${ }^{[16]}$.

Clubfoot (CTEV) is the most common orthopaedic problem in newborn. CTEV is characterized by an equine and varus hind foot, an adducted and supine forefoot, not reducible. Orthopedic problems are sometimes suspected prenatally but final diagnosis must be done only 
after thorough clinical examination at birth. These deformations can be corrected with simple orthopaedic procedures if detected in immediate neonatal life and surgical corrections, if needed before walking. It has excellent prognosis even with simple orthopaedic procedures ${ }^{[17]}$.

The limitations of our study were conducted in a tertiary care centre with specialized new born care unit that caters people from poor socio-economic status. Mothers and neonates with complications were more than that in the community. This study was done at the neonatal period, there is a possibility of more cases with anomalies identified at later part of age. Because of these factors, our study population could not be representative of general population. Also, a follow up of all these children will enable us to understand the longterm outcome in this group. Predictors of congenital malformations in neonates need to be studied in future.

\section{Conclusion}

This study shows that the congenital malformations are still a burden to address and the pattern of congenital surgical anomalies varies from centre to centre. The formulation of screening protocols and implementation of programs that facilitate early identification and treatment of congenital anomalies are dependent on the disease burden and pattern. Studies of this sort, conducted as multi-centric studies would contribute the understanding of pattern and prevalence of congenital anomalies which in turn enables the government to plan appropriate intervention measures and its timing to reduce the early childhood morbidity.

\section{Acknowledgements}

Funding: None

Conflict of Interest: None

Ethical Approval: Institutional ethical committee Approved

\section{References}

1. World Health Organization. Section on congenital anomalies. Available from: http://www.who.int/mediacentre/factsheets /fs370/en/ Accessed February 2019.

2. UNICEF. Neonatal Health. Available at Unicef.in/whatwedo/2/Neonatal-Health

3. National health Portal of India. Section on congenital anomalies (birth defects). Available at https://www.nhp.gov.in/disease/gynaecolo gy-and-obstertrics/congenital-anomaliesbirth-defects

4. Infant Mortality rate in Tamilnadu, NITI Aayog, Government of India, http://niti.gov.in/content/infant-mortalityrate-imr-1000-live-births, accessed on $20^{\text {th }}$ February 2019.

5. Shija JK. Neonatal surgical problems in Dar-es-Salaam, Tanzania. Med J Zambia 1977;11:139-43.

6. Tirumani HB, Khatija S. Profile of congenital malformations in a tertiary care level neonatal intensive care unit. Int J Contemp Pediatr 2017;4:1634-7.

7. Dolk, H., Loane, M., \& Garne, E. (2010). The Prevalence of Congenital Anomalies in Europe. Advances in Experimental Medicine and Biology, 349-364.

8. Pandala P, Kotha R, Singh H, Nirmala C. Pattern of congenital anomalies in neonates at tertiary care centre in Hyderabad, India: a hospital based prospective observational study. Int $\mathrm{J}$ Contemp Pediatr 2019;6:63-7.

9. Pabbati J, Subramanian P, Sudharshan RC, Sadhana N, Rao R. Study on incidence of congenital anomalies in a rural teaching hospital, Telangana, India. Int J Contemp Pediatr 2016;3:887-90.

10. Ara A, Kumar D, Dewan D, Digra NC. Incidence of congenital anomalies in a rural population of Jammu - A prospective study. Indian J Public Health 2018;62:18892 
11. Kalra A, Kalra K, Sharma V, Singh M, Dayal RS. Congenital malformations. Indian Pediatr. 1984;24:945-50.

12. Suguna Bai NS, Mascarene M, Syamalan K, Nair PM. An etiological study of congenital malformation in the newborn. Indian Pediatr. 1982;19:1003-7.

13. Mathur BC, Karan S, Vijaya Devi KK. Congenital malformations in the newborn. Indian Pediatr. 1975;12:179-83.

14. Cleft Palate Craniofac J. 2013 Mar;50(2):224-30. doi: 10.1597/10-223. Epub 2011 Sep 9.

15. Wiggman K, Larson M, Larson O, Semb $\mathrm{G}$, Brattstorm V. The influence of the initial width of the cleft palate patients with unilateral cleft lip and palate related to the final treatment outcome in the maxilla at 17 years of age. Eur J Ortho 2013 Jun;35(3):335-340

16. De Wals P, Tairou F, Van Allen MI, UhSH, Lowery RB Sibbald B, Evans JA, Van den Hof MC, Zimmer P, Crowley M, et al. Reduction in neural tube defects after folic acid fortification in Canada. N Engl J Med 2007 Jul 12;357(2):135-142

17. Delpont, M., Lafosse, T., Bachy, M., Mary, P., Alves, A., \& Vialle, R. (2015). Anomalies des pieds à la naissance. Archives de Pédiatrie, 22(3), 331-336. doi:10.1016/j.arcped.2014.11.009. 